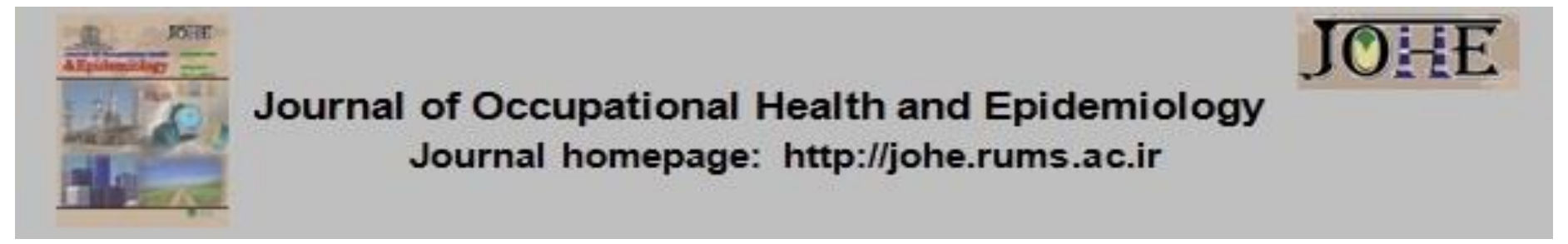

\title{
The Role of Continuing Education in Protecting Nurses against COVID-19 Infection
}

Mohammad Ali Zakeri ${ }^{1}$, Mahlagha Dehghan ${ }^{2 *}$

1. MSc in Nursing, Non-Communicable Diseases Research Center, Rafsanjan University of Medical Sciences, Rafsanjan, Iran. 2. Assistant Prof., Nursing Research Center, Kerman University of Medical Sciences, Kerman, Iran.

\section{Citation: Zakeri MA, Dehghan M. The Role of Continu
against COVID-19 Infection. JOHE. 2021; 10(2):64-6.}

\author{
Article Info \\ * Corresponding author: Mahlagha Dehghan, \\ E-mail: m_dehghan86@yahoo.com \\ Article history \\ Received: Apr 2020 \\ Accepted: Jun 2021 \\ 10.52547/johe.10.2.64
}

Print ISSN: 2251-8096

Online ISSN: 2252-0902

Peer review under responsibility of Journal of Occupational Health and Epidemiology

\section{Dear Editor,}

Prevention is the best strategy to reduce infection. The widespread novel infectious diseases have been diagnosed and controlled with delay [1]. The rapid spread of COVID-19 has exposed nurses, the frontline caregivers, to such an infection. All medical centers and hospitals have paid particular attention to the education and educational methods to prevent nurses' infection. This education has been important for nurse managers. Studies have shown that nursing education programs on infection control measures have led to significant advances in nurse knowledge and practice, significantly affecting infection control [24]. In the study of Gaikwad et al., the educational intervention has had a significant impact on the development of nurses' knowledge about infection control measures (pre-test score: $3.94 \pm 2.3$ vs. post-test score: $15.33 \pm 2.4$ ) [4]. According to Gomarverdi et al., nurse adherence to the standard precautions has increased from $19.87 \pm$
4.44 at pre-test to $29.20 \pm 5.00$ and $28.40 \pm 4.37$ at two- and six-week post-test, respectively [3]. Also, Yousef et al. show statistically significant improvement in the nurses' infection control measures $(48.93 \pm 16.67$ vs. $113.37 \pm 10.61)$ and total knowledge $(80.70 \pm 18.48$ vs. $174.83 \pm 18.37)$ after the educational program [2].

Implementing a nursing education program can help nurses be prepared for critical situations such as COVID -19 disease. Ghanbari et al. show that the nursing education program against natural disasters improves the knowledge, attitude, practice, and readiness of nurses [5]. Also, Gresh et al. have shown that online education for 135 nursing students and 15 clinical instructors in COVID-19 disease improve factors, including assessment and analytic, policy development/program planning, communication, cultural competency, community dimensions of practice, public health sciences, financial planning/ evaluation/management, and leadership /system thinking skills [6]. 
In the prevalence of COVID-19 disease, some hospitals have used educational content involving personal protective equipment (PPE), hand hygiene, ward disinfection, medical waste management, patient-care device sterilization, and occupational exposure management. Nurses should know how to use PPE by continuing education in practice and theory. PPE includes highly recommended equipment to protect nurses. PPE plays a very important role in reducing the infection of nurses, and education has a significant effect on its proper use. Some hospitals have used recorded educational videos, the details of which have been made available to nurses in social groups such as WeChat [7]. Such measures have increased the information of nurses and prevented the transmission of COVID-19 disease to them.

Nurse managers can increase the quality of education by monitoring and assessing the educational feedback in practice before nurses contact patients.

One of the important issues in the correct and principled learning of nurses is to study the factors affecting the quality of their continuing education, which significantly, in turn, affects their protection. Health care providers, especially nurses, are under high psychological pressure due to the high risk of infection, unsuitable equipment against infection, isolation, burnout, as well as being away from family. These conditions can cause many psychological problems for nurses, thus affecting their decisions and participation in medical care [8]; they can also affect the education of nurses.

To relieve the psychological pressure of nurses, head nurses in some hospitals and medical centers share the necessary information about the equipment and resources with them in regular meetings and talk about emergency assistance in critical situations. Psychotherapists can help in the case of symptoms of anxiety or insomnia in nurses [7].

Also, psychological intervention teams are required to reduce the psychological damage of COVID-19 among the nursing staff. Further, a wide range of psychological services, including psychotherapeutic counseling and brochures, are needed [9] to train nurses. These measures can indirectly play an important role in the observance and avoidance of occupational exposures, helping nurses cope with potential stress and depression and increasing their satisfaction. They identify the psychological problems of nurses and improve their condition, motivating them to involve in personal protection, follow precautionary instructions, and participate in continuing education. To motivate nurses and encourage them to follow safety principles, some support groups, not the health care system, present safety tips in the form of motivational sentences in different hospital wards.

The approval and encouragement by the hospital manager and government, the preparation of infection control instructions, specialized equipment, and facilities for COVID-19 infection management are among the factors potentially encouraging health care workers to implement and consider precautionary measures [10] to pave the way for nurses to participate in the education. Nurses experience more anxiety and stress because they deal with ill patients and difficult working conditions [11, 12], affecting their strength and concentration on learning, thus the quality of their training. Therefore, education should be done at appropriate times and according to the psychological dimensions of nurses. Managers' attention to the mental state, the training of stress coping strategies, and specialized education to control infection can protect nurses against the COVID-19 epidemic.

\section{References}

1. Omrani AS, Shalhoub S. Middle East respiratory syndrome coronavirus (MERS-CoV): what lessons can we learn? J Hosp Infect 2015; 91(3):188-96.

2. Yousef YE, Elashir UM, Mahmoud SR, Maghraby $N$. The effect of nursing educational program on knowledge and practice of nurses regarding infection control measures for children under hemodialysis. Egyptian Nursing Journal 2019; 16(1):1-9.

3. Gomarverdi S, Khatiban M, Bikmoradi A, Soltanian AR. Effects of a multi-component educational intervention on nurses' knowledge and adherence to standard precautions in intensive care units. J Infect Prev 2019; 20(2):83-90.

4. Gaikwad UN, Basak S, Kulkarni P, Sande S, Cahavan S, Mudey G, et al. Educational Intervention to Foster Best Infection Control Practices among Nursing Staff. International Journal of Infection 2018; 5(3):e81531. doi: 10.5812/iji..

5. Ghanbari V, Maddah SS, Khankeh HR, Karimloo M, Ardalan A. The Effect of a Disaster Nursing Education Program on Nurses' Preparedness for Responding to Probable Natural Disasters. Iran Journal of Nursing 2011; 24(73):72-80.

6. Gresh A, LaFave S, Thamilselvan V, Batchelder $A$, Mermer J, Jacques $K$, et al. Service learning in public health nursing education: How COVID19 accelerated community-academic partnership. Public Health Nurs 2021; 38(2):248-57. 
7. Huang L, Lin G, Tang L, Yu L, Zhou Z. Special attention to nurses' protection during the COVID-19 epidemic. Crit Care 2020; 24(1):120.

8. Rana W, Mukhtar S, Mukhtar S. Mental health of medical workers in Pakistan during the pandemic COVID-19 outbreak. Asian J Psychiatr 2020; 51:102080.

9. Kang L, Li Y, Hu S, Chen M, Yang C, Yang BX, et al. The mental health of medical workers in Wuhan, China dealing with the 2019 novel coronavirus. Lancet Psychiatry 2020; 7(3):e14.

10. Cai H, Tu B, Ma J, Chen L, Fu L, Jiang Y, et al. Psychological Impact and Coping Strategies of Frontline Medical Staff in Hunan Between
January and March 2020 During the Outbreak of Coronavirus Disease 2019 (COVID-19) in Hubei, China. Med Sci Monit 2020; 26:e924171.

11. Zakeri MA, Dehghan M, Heidari FG, Pakdaman $\mathrm{H}$, Mehdizadeh $\mathrm{M}$, Ganjeh $\mathrm{H}$, et al. Mental health outcomes among health-care workers during the COVID-19 outbreak in Iran. Mental Health Review Journal 2021; 26(2):152-60.

12. Zakeri MA, Hossini Rafsanjanipoor SM, Zakeri $M$, Dehghan $M$. The relationship between frontline nurses' psychosocial status, satisfaction with life and resilience during the prevalence of COVID-19 disease. Nurs Open 2021; doi: 10.1002/nop2.832. 